\title{
Air-Conditioning Unit Performance Analysis Equipped with a Shaded Condenser
}

\section{Dr. Maher Shehadi, Purdue Polytechnic Institute}

Dr. Shehadi is an Assistant Professor of Mechanical Engineering Technology (MET) at Purdue University. His academic experiences have focused on learning and discovery in areas related to HVAC, indoor air quality, human thermal comfort, and energy conservation. While working with industry, he oversaw maintenance and management programs for various facilities including industrial plants, high rise residential and commercial buildings, energy audits and condition surveys for various mechanical and electrical and systems. He has conducted several projects to reduce carbon dioxide and other building emission impacts by evaluating and improving the energy practices through the integration of sustainable systems with existing systems. His current research focuses on engaging and educating students in sustainable and green buildings' design and energy conservation. He is currently investigating various ways to reduce energy consumption in office buildings. 


\title{
Air Conditioning Unit Performance Analysis Equipped with a Shaded Condenser
}

\begin{abstract}
Condensers are used in chillers and in air-conditioning systems to reject heat from the refrigerant to the outdoor air and to help in liquefying the refrigerant as it passes through its tubes. Reducing the surrounding air temperature or the surface temperature for the condenser would help in eliminating an additional source of heat into the refrigerant and lower the temperature of air surrounding the condensers which would enhance the air-conditioning system performance.

A capstone project in the School of Engineering Technology at Purdue University conducted an experimental and analytical study to investigate the performance of a 3 ton-refrigerant (TR) airconditioning unit, installed in a residential house, while shading its condenser. The surface temperature of the tubes exiting the condenser were measured and recorded along with the evaporator temperature. The study looked into improvement in the coefficient of performance (COP) of the cycle. Data for the a 3 TR air-conditioning split unit were used to simulate the $\mathrm{COP}$ and improvement in the system performance. Experimental and analytical performances were simulated at different evaporator and outdoor temperatures. The experimental results for the 3-TR unit showed 12-39\% improvement in the COP of the cycle under various evaporator temperatures, while the simulated results showed higher improvements than the experimental.

The project was assessed through biweekly progress reports, presentations, final report and team work which satisfied many of the ABET outcomes such as applying knowledge, technical skills, mathematics and science in engineering technology problems, conducting tests and experiments, analyzing results, team work skills, and oral and written communication. This project and similarly embedded projects in courses are thought to increase students' knowledge by involving them in an active learning environment while solving or analyzing real world problems and challenges.
\end{abstract}

\section{Introduction}

Heating, ventilation and air-conditioning (HVAC) systems are the largest electricityconsuming sector in residential buildings in the U.S. [1]. According to [2], the U.S. Energy Information Administration indicated that more than $40 \%$ of the total energy consumption in the U.S. is in residential buildings. This figure is slightly less in Canada with $30 \%$ of the country's energy usage going into buildings of which $16 \%$ is by residential buildings [3]. The world equipment demand for heating, ventilation, and air conditioning (HVAC) has increased from 50 
billion US dollars in 2004 to more than 90 billion US dollars in 2014 and for the US almost 11 billion to 19 billion US dollars over the same period [4]. The average office building in the U.S. utilizes $14 \%$ of its energy specifically for cooling [5]. While this may not be the largest chunk of energy usage in the average office building, it is still the second largest. On the other hand, the total HVAC energy consumption in residential buildings can reach up to $30 \%$ [6] and in office buildings up to $39 \%$ including energy needed for fans in the system, cooling, heating, pumps and cooling towers [7]. Thus, a reduction in the HVAC energy consumption load would reflect a significant reduction in the total energy consumed.

According to Madison Gas and Electric Company, “on average, a U.S. office building spends nearly 29 percent of its operating expenses on utilities, and the majority of this expenditure goes toward electricity and natural gas. For the average office building, energy costs can exceed $\$ 30,000$ per year,'”[5].

Cooling towers contributes toward $6 \%$ of the energy consumption by office buildings [7]. Whatever type of refrigerating system is being used in the HVAC system, it is fundamental to minimize the required heat extraction and to keep the difference between condensing temperature $\left(\mathrm{T}_{\mathrm{c}}\right)$ and evaporating temperature $\left(\mathrm{T}_{\mathrm{e}}\right)$ as small as possible [8]. Most of the previous studies have focused on energy consumption by the HVAC system as a whole, but none has investigated possible energy savings by reducing the temperature of the condenser units.

With the condenser being exposed to the solar flux from the sun, its performance in rejecting heat from the refrigerant could become impeded especially with high outdoor temperatures. When direct sunlight hits the condenser, it increases the temperature of the condenser which makes heat transfer more difficult for the system causing a decrease in its performance.

Energy conservation in buildings has become a prime objective for energy policy at regional, national and international levels [9]. For that, this research investigated HVAC system performance when the condenser of the unit was shaded to check any possible energy conservation means. An experimental and analytical approaches were followed. This project was done during capstone project in the Mechanical Engineering Technology (MET) Department with focus on air-conditioning and refrigeration fields. The project met many ETAC ABET outcomes such as (a) applying knowledge and technical skills in engineering technology activities, (b) applying knowledge of mathematics, science, engineering and technology to engineering technology problems that require extensive practical knowledge, (c) conducting tests and measurements, analyzing and interpreting experiments, (d) improving team work skills, (e) identifying, analyzing and solving narrowly defined engineering technology problems, (f) applying oral and written communications skills, and (i) having a commitment to quality, timeliness and continuous improvement.

\section{Methods and Procedures}

A residential house occupied by 3 residents in the city of Kokomo, IN was considered to conduct the experimental testing. The coefficient of performance (COP) of the system, as defined in 
equation (1), was used to check on any improvements when the unit was shaded versus unshaded.

$C O P=\frac{T_{e}}{T_{c}-T_{e}}$

where $T_{c}$ and $T_{e}$ are the condenser and evaporator temperatures, respectively. A 3 TR airconditioning unit was installed in the house. Thermocouples type $\mathrm{T}$ were used to measure the surface temperature of the refrigerant pipes at the inlet and exit of the condenser, as shown in Figure 1. The average of the inlet and exit was used as $\mathrm{T}_{\mathrm{c}}$ in equation (1). The evaporator temperature inside the house was set to 5,8 and $10^{\circ} \mathrm{C}$.

Different options of shading were available such as wooden trellis, trees and plantings, building orientation, or fabric structure as was used in this project. A canopy fabric was used to shade the outdoor condenser unit, as shown in Figure 2. The canopy needed to not only shade the sun incoming flux from the condenser, but it was important for it not to trap hot air which can have adverse effects on the condenser and can cause its temperature to increase and it was needed to be installed in a way to drain any rain down and away from the condenser. For that, the forth pole of the canopy was removed and the canopy was directed as shown in Figure 2. The condenser temperatures were then measured for each of the three evaporator temperatures for approximately 20 days under each evaporator temperature setting. The procedures were repeated twice, one time with a shaded condenser and another with no shade. The temperature was logged during summer time from June till September from 6:00 am till 9:00 pm. The logged data were sorted and categorized according to the average outdoor temperature.

The improvement in the COP for the shaded days over unshaded was checked using equation (2).

$I=\frac{C O P_{s}-C O P_{u}}{\operatorname{COP}_{u}}$

where I is the improvement factor, and the subscripts s and u stand for shaded and unshaded COP, respectively. 


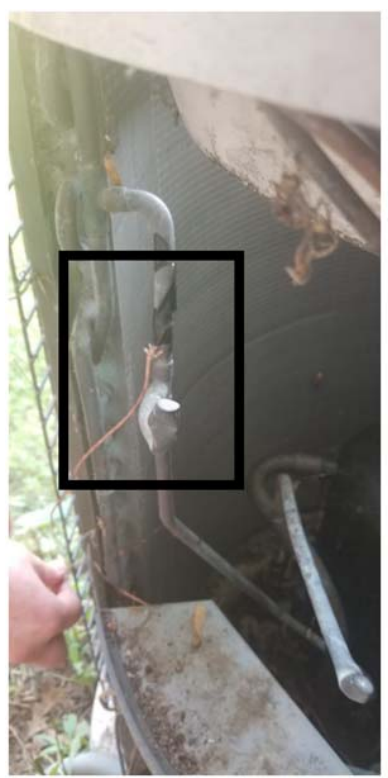

(a)

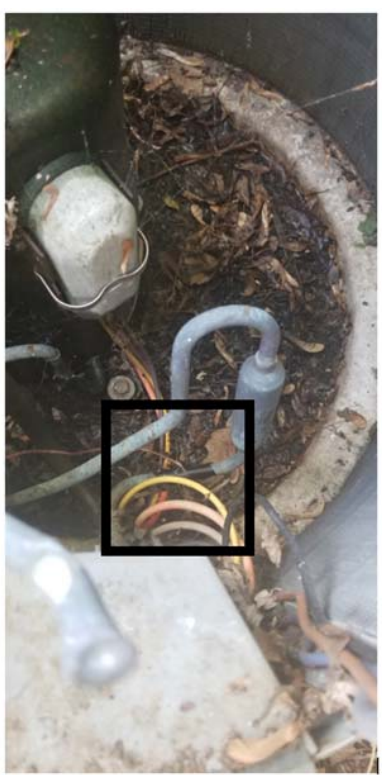

(b)

Figure 1. Thermocouples wrapped on the refrigerant pipes across the condenser. Note the temperature of the pipe leaving the condenser was used; the one entering the condenser was measured for reference purposes only

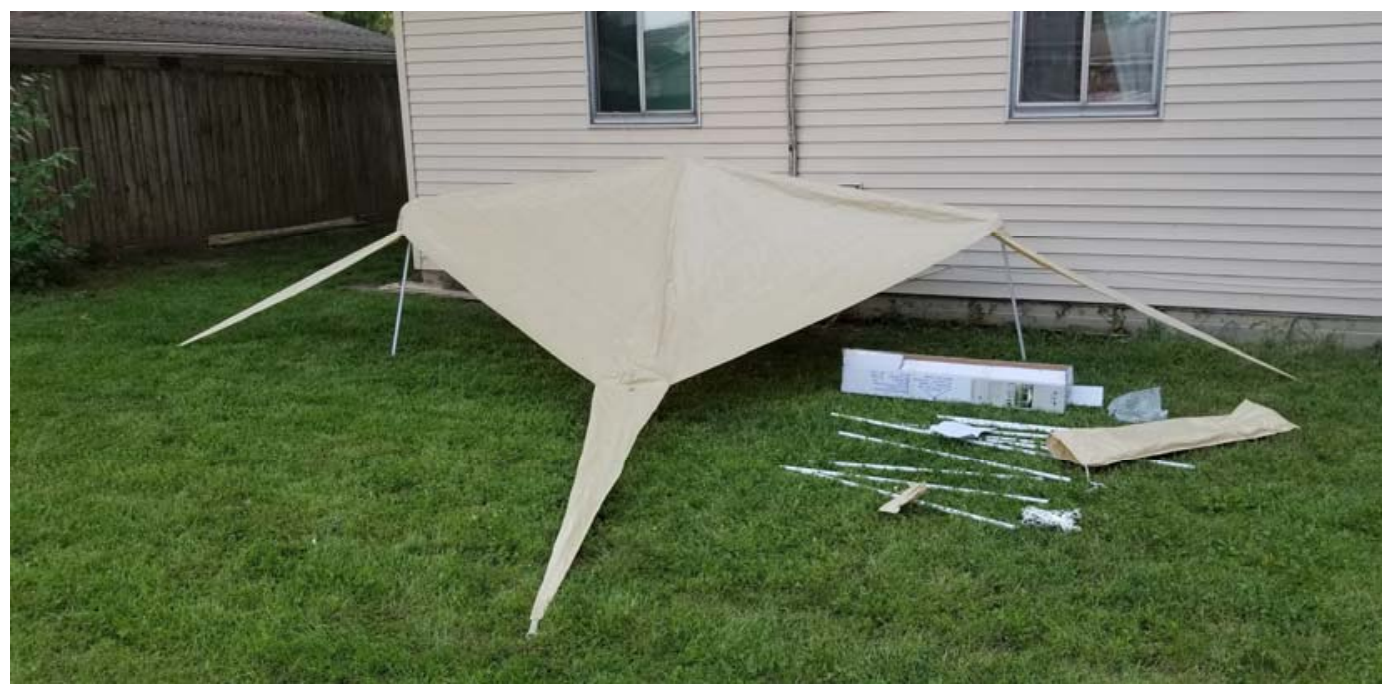

Figure 2. Canopy used to shade the condenser

For the simulated part of the study, data for a 3-TR unit were simulated from Carrier website [10] and the results were compared to the experimental ones. The evaporator temperature was simulated with the same 3-different temperatures used for the experimental study. To calculate the condenser temperature for both cases, shaded and unshaded, it was assumed that the 
difference in the heat rejected by the condenser in both cases was solely due to the solar heat gain by the condenser as shown in equation (3).

$\mathrm{Q}_{\mathrm{c}, \mathrm{u}}=\mathrm{Q}_{\text {sun }}+\mathrm{Q}_{\mathrm{c}, \mathrm{s}}$

$\mathrm{Q}_{\text {sun }}=q^{\prime \prime} \times \mathrm{A}_{\mathrm{c}}$

where $\mathrm{Q}_{\mathrm{c}, \mathrm{u}}$ is the unshaded condenser heat rejected, $\mathrm{Q}_{\mathrm{c}, \mathrm{s}}$ is the shaded condenser heat rejected, and $\mathrm{Q}_{\text {sun }}$ is the solar heat gain, respectively. The solar heat gain was calculated in equation (4) using an estimated value of solar flux $5.84 \mathrm{~kW} / \mathrm{m}^{2}$, based on $6-6.5 \mathrm{kWh} / \mathrm{m}^{2} /$ day [11]. Following equations (3) and (4), the logarithmic mean temperature difference " $\triangle \mathrm{TLM}$ " was solved for both the shaded and unshaded cases using equation (5) and (6), where $\mathrm{Q}_{\text {load }}$ and $\mathrm{W}_{\text {in }}$ are the cooling load and compressor work, respectively. Equation (5) provided the unshaded condenser heat rejected and then using equation (3) the shaded condenser heat was obtained $\left(\mathrm{Q}_{\mathrm{c}, \mathrm{s}}\right)$.

$\mathrm{Q}_{\mathrm{c}, \mathrm{u}}=\mathrm{Q}_{\text {load }}+\mathrm{W}_{\text {in }}$

$\mathrm{Q}_{\mathrm{c}}=\mathrm{UA} . \Delta \mathrm{TLM}$

Assuming a constant split temperature " $\mathrm{T}_{\mathrm{ss}}=30^{\circ} \mathrm{C}$ ", where $\mathrm{T}_{\mathrm{ss}}=\mathrm{T}_{\mathrm{c}}-\mathrm{T}_{\mathrm{a}}\left(\mathrm{T}_{\mathrm{a}}\right.$ is the air inlet temperature into the condenser), the temperature difference for $\left(T_{c, u}-T_{o, u}\right)$ and $\left(T_{c, s}-T_{o, s}\right)$ was obtained for unshaded and shaded cases by solving each equation (7) and (8), respectively.

$\Delta \mathrm{TLM}_{\mathrm{u}}=\frac{(T c, u-T o, u)-(T c, u-T a)}{\ln \left(\frac{T c, u-T o, u}{T c, u-T a}\right)}$

$\Delta \mathrm{TLM}_{\mathrm{s}}=\frac{(T c, s-T o, s)-(T c, s-T a)}{\ln \left(\frac{T c, s-T o, s}{T c, s-T a}\right)}$

The outdoor temperature for both cases shaded and unshaded was obtained by applying energy balance over the condenser as shown in equations (9) and (10).

$\mathrm{Q}_{\mathrm{c}, \mathrm{u}}=\rho \dot{V} \times C p_{\text {air }} \times\left(T_{o, u}-T_{a}\right)$

$\mathrm{Q}_{\mathrm{c}, \mathrm{s}}=\rho \dot{V} \times C p_{\text {air }} \times\left(T_{o, s}-T_{a}\right)$

where $\rho$ was the density of air, $\mathrm{C}_{\mathrm{p}}$ was the specific heat of air, and $\dot{V}$ is the volumetric flow rate of air rejected by the condenser fans.

Three evaporator temperatures were considered $5^{\circ} \mathrm{C}, 8^{\circ} \mathrm{C}$ and $10^{\circ} \mathrm{C}$ with outdoor temperatures ranging between $19-26^{\circ} \mathrm{C}$. 


\section{Results}

For either the experimental or simulated cases, the COP was shown to decrease as the condenser temperature increased. The simulated COP for both shaded and unshaded are plotted versus the condenser temperature in Figure 3 while keeping the evaporator temperature at $5^{\circ} \mathrm{C}$ and outdoor temperature at $35^{\circ} \mathrm{C}$. This in return confirms that reducing the condenser temperature, whether by providing a shade to block the solar flux or by other means, can increase the unit performance.

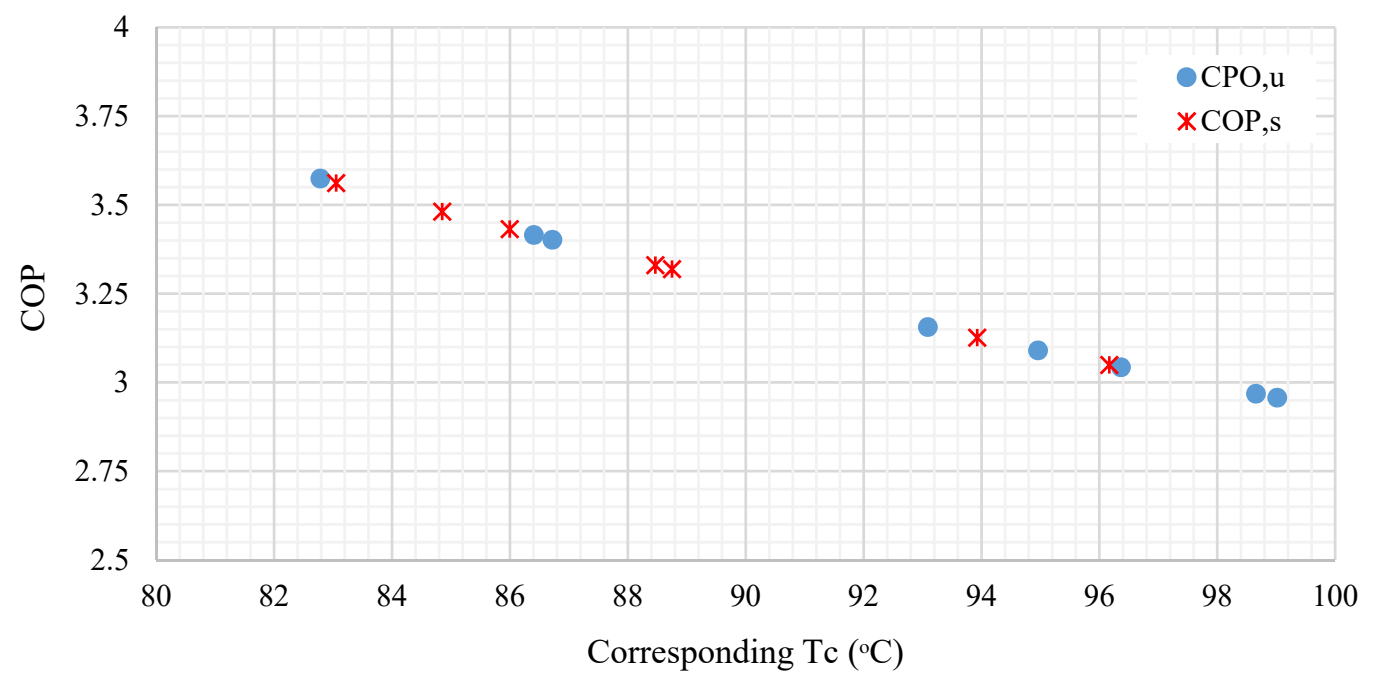

Figure 3. COP versus condenser temperature

For experimental data, the average of the outdoor temperature between 6:00 am - 9:00 pm was used to sort the data. The simulation for the 3-TR followed the same range of outdoor temperatures from $19-26^{\circ} \mathrm{C}$ for comparison reasons. The improvement in the COP of the 3-TR units was plotted in Figure 4 for both experimental and simulation approaches. It was clear from either the experimental or the simulated results that the shaded condenser provided higher COP than unshaded ones. The simulated improvement in COP decreased with the outdoor temperature and ranged between $22-31 \%, 25-38 \%$ and $27-43 \%$ for evaporator temperatures of $5^{\circ} \mathrm{C}, 8^{\circ} \mathrm{C}$, and $10^{\circ} \mathrm{C}$, respectively. The experimental improvement for the same respective evaporator temperatures were $12-31 \%, 17-37 \%$ and $21-39 \%$ over the same range of outdoor temperature from $19-26^{\circ} \mathrm{C}$. A major reason for the discrepancy in the results between experimental and simulated results could be the maintenance of the actual tested unit, error in experimental setup and testing procedures, or trapped air effect on the inlet air temperature. Despite the differences, the two approaches agreed on higher improvements in the COP with higher evaporator temperatures and lower outdoor temperatures. This was expected as the cooling load by the unit would be less. 


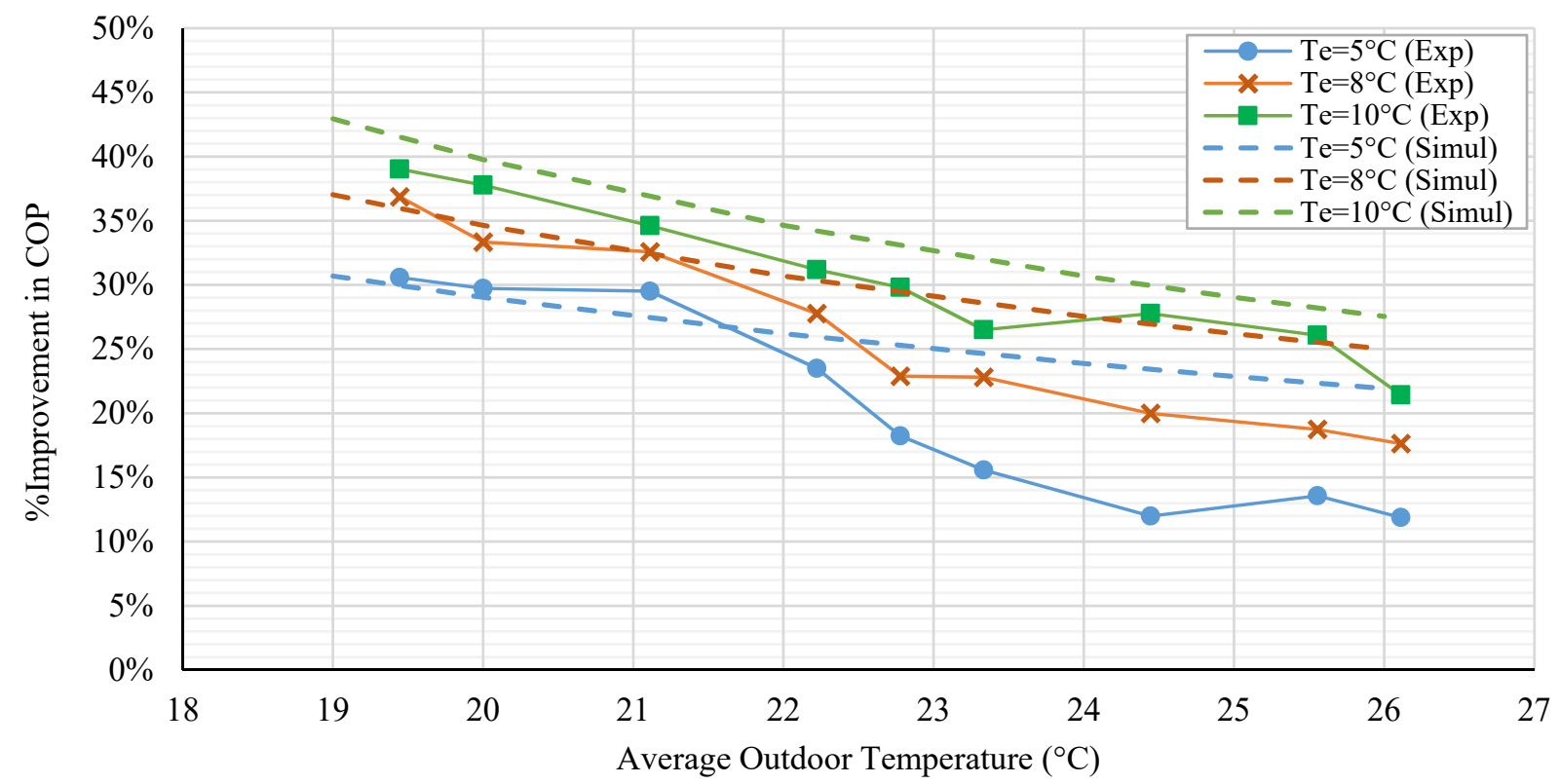

Figure 4. Percent improvement in the COP for various evaporator and outdoor temperatures using experimental and analytical approaches

\section{Project Assessment}

The project was assessed using different assessment tools such as biweekly reports, final report, presentation and team work assessment. Through the continuous submission of biweekly progress reports, the team met many ABET outcomes such as (a) applying knowledge, techniques and skills to engineering technology activities, (b) applying knowledge of mathematics, science, engineering, and technology to engineering technology problems, (c) conducting tests, measurements, calibration and improving processes, (e) engineering technology problem solving, (f) improving written and oral communication skills, and (i) commitment to quality, timeliness and continuous improvement. Some of the project deliverables used to assess ETAC ABET outcomes are shown in Table 1. 
Table 1. Project deliverables and its relation to ABET outcomes

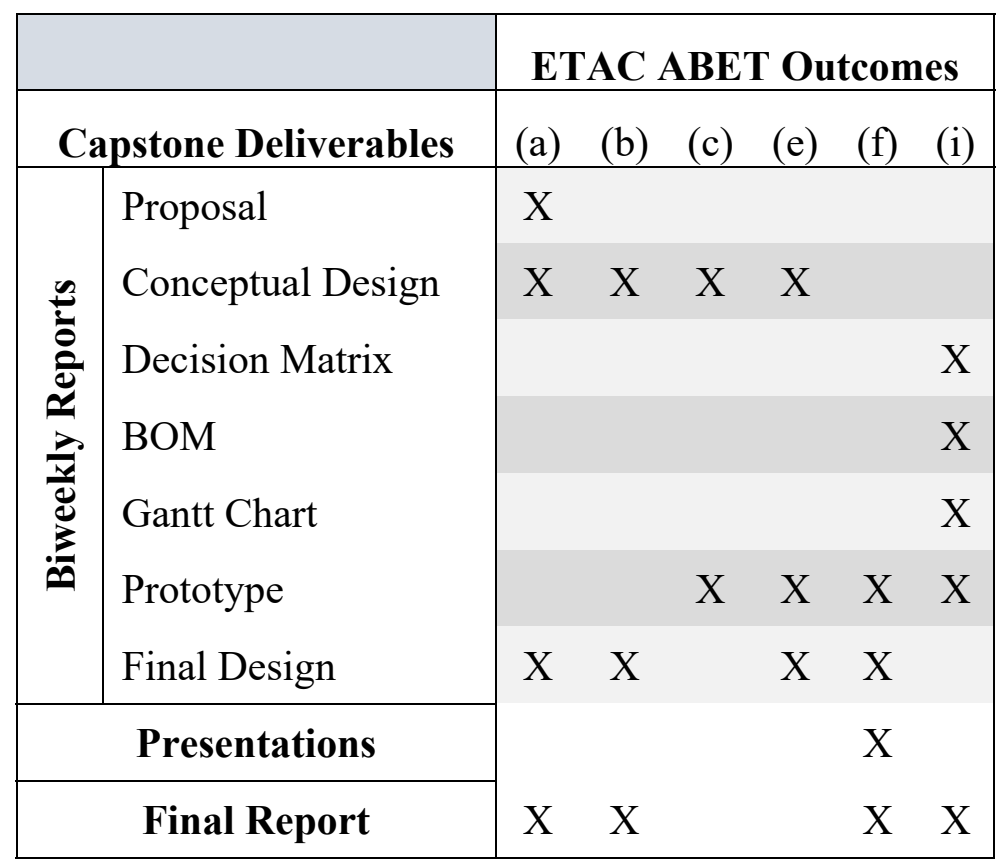

The final project grade was based on biweekly reports (15\%), final report (50\%), presentation $(25 \%)$ and team work and product evaluation $(10 \%)$ as shown in Figure 5. Biweekly reports are as shown in Table 1. The team evaluation was done based on the team self-evaluation and the project supervisor. The teams had to evaluate their team members and the themselves which contributed to half the team evaluation grade ( $5 \%$ of the total final grade). The other half was based on the project supervisor evaluation which included some oral questions to test the member participation and knowledge towards the project. 


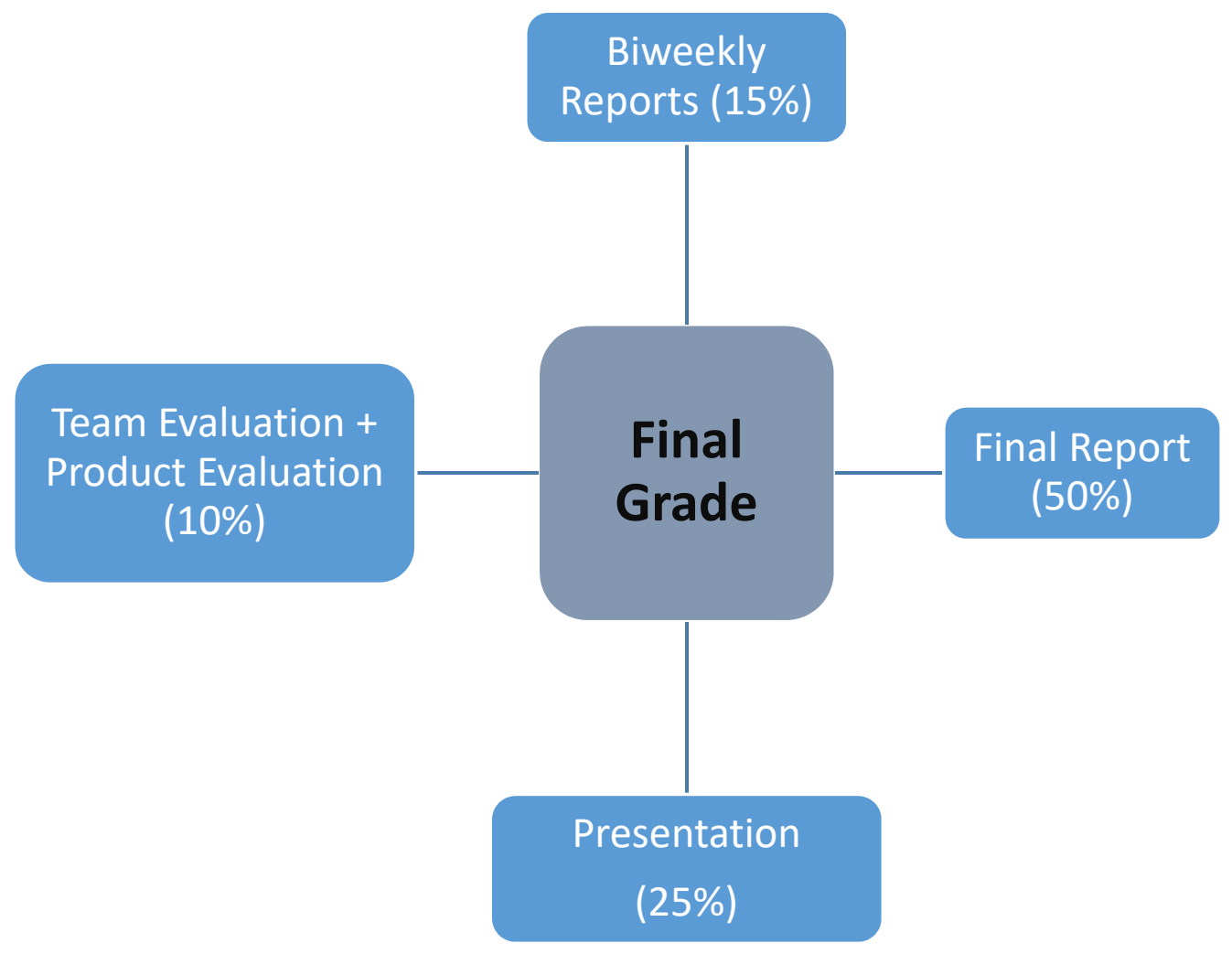

Figure 5. Capstone assessment structure

\section{Conclusions}

A capstone project investigated improvement in a 3 TR air-conditioning unit performance using an experimental and analytical approach. The project proposed shading the condenser and the coefficient of performance of the cycle was evaluated when the condenser was shaded and unshaded. The improvement for the 3-TR unit was between 10-39\% based on experimental results and between $22-44 \%$ based on simulation for different evaporator and outdoor temperatures. The improvement in COP increased with higher evaporator temperatures and lower outdoor temperatures. Higher evaporator temperatures would result in lower cooling loads and thus higher COP. The same interpretation applies for lower outdoor temperatures.

A major reason for the discrepancy in the results between experimental and simulated results could be the maintenance of the actual tested unit or errors in experimental setup and testing procedures. If the residential HVAC units are not service regularly, a condition that is very common for HVAC units in residential buildings [12], the unit is expected to perform below its best designed performance. Other reasoning could be the humidity effect which was not counted for, the possibility of hot air trap under the shade, and measurements error which were as low as $1.7 \%$ and up to $35.32 \%$ in some other cases. 
The project, through its implementation, met many of the ABET outcomes such as, applying knowledge, mathematics and science in engineering technology problem solving, improving students' measurements and testing skills, their communication skills, project management skills and team work, as well.

\section{References}

[1] D. Huyen and S. Kristen S., "Data-driven evaluation of residential HVAC system efficiency using energy and environmental data," Energies, vol. 12, pp. 188-203, 2019. doi:10.3390/en12010188

[2] M. Shehadi, "Office thermostat accuracy and reliability," Journal of Engineering Technology, Spring 2019, pp. 16-27, 2019.

[3] NRCan, National Energy Use Database - Energy Use Handbook, Natural Resources Canada, 2005. Available online: http://oee.nrcan.gc.ca/corporate/statistics/neud/dpa/data_e/databases.cfm?attr=0

[4] M. Mujahid, P. Gandhidasan, S. Rehman, and L. Al-Hadhrami, "A Review on Desiccant based Evaporative Cooling Systems," Renewable and Sustainable Energy Reviews, vol. 45, pp. 145-59, 2015. Accessed online: http://doi.org/10.1016/j.rser.2015.01.051.

[5] Madison Electric Company., Managing Energy Cost in Office Buildings, [Brochure] Madison, WI: Author, 2010.

[6] EIA (US Energy Information Administration). Annual Energy Outlook 2017, 2017. Accessed May 2019. Available at: https://www.eia.gov/outlooks/aeo/data/browser/

[7] RET, HVAC energy breakdown. Guide to Best Practice Maintenance and Operation of HVAC Systems for Energy Efficiency; pp. 36-37, 2012. Retrieved from https:/www.environment.gov.au/system/files/energy/files/hvac-factsheet-energy-breakdown.pdf

[8] IIR, How to improve energy efficiency in refrigerating equipment, International Institute of Refrigeration, $17^{\text {th }}$ Informatory Note on Refrigerating Technologies. Paris, FR: International Institute of Refrigeration, 2003.

[9] L. Perez-Lombard, J. Ortiz, and C. Pout, C., "A review on buildings energy consumption information," Energy and Buildings, vol. 40, pp. 394-398, 2008.

[10] Carrier Inc., 2018. Accessed Online: https://files.carrier.com/marine-offshore/en/worldwide/contentimages/13050-76-IOM-30GXHXC.pdf

[11] NREL, Solar Maps: Direct Solar Irradiance, 2019. Accessed online: https://www.nrel.gov/gis/solar.html

[12] K. Cetin and A. Novoselac, "Single and multi-family residential central all-air HVAC system operational characteristics in cooling-dominated climate," Energy and Buildings, vol. 96, pp. 210 $220,2015$.

\section{Authors' Bio}

Dr. Shehadi is an Assistant Professor of Mechanical Engineering Technology (MET) at Purdue University. His academic experiences have focused on learning and discovery in areas related to HVAC, indoor air quality, human thermal comfort, and energy conservation. While working with industry, he oversaw maintenance and management programs for various facilities including industrial plants, high rise residential and commercial buildings, energy audits and condition surveys for various mechanical and electrical and systems. He has conducted several projects to reduce carbon dioxide and other building emission impacts by evaluating and improving the energy practices through the integration of sustainable systems with existing systems. His current research focuses on engaging and educating students in sustainable and green buildings' design and energy conservation. He is currently investigating various ways to reduce energy consumption in office buildings. 